Perforator Flaps. Plast Reconstr Surg. 2007 Nov, 120(6): 1551-1556.

4. Hashimoto I., Abe $Y_{\text {., }}$ Ishida $S_{.,}$et al. (2016).Development of Skin Flaps for Reconstructive Surgery: Random Pattern Flap to Perforator Flap. The Journal of Medical Investigation, 63: 159-162.

5. Vasile J.V., Newman T., Rusch D.G., et al. (2009). Anatomic Imaging of Gluteal Perforator Flaps without Ionizing Radiation: Seeing Is Believing with Magnetic Resonance Angiography. J Reconstr Microsurg. 2010 Jan, 26(1): 45-57.
6. Hallock G.G. (2009). A Primer of Schematics to Facilitate the Design of the Preferred Muscle Perforator Flaps.Plast Reconstr Surg. 2009 Mar, 123(3):1107-1015.

7. Hoàng Minh Tú (2020). Nghiên cứu giải phẫu nhánh xuyên động mach mông trên ở người Việt Nam, Luận án Tiến sĩ Y họ.

8. Nguyển Văn Thanh(2018). N Nghiên cứu vạt nhánh xuyên đông mach mông trên kết hợp hút áp lực âm trong điều trị vết loét mạn tính cung cut, Luận án Tiến sĩ Y học.

\title{
ĐÁNH GIÁ KẾT QUẢ LÀM MỎNG THÌ ĐẦU VẠT ĐÙI TRƯớC NGOÀI TRONG PHẪU THUÂTT TẠO HÌNH
}

\section{TÓM TẮT}

Mục tiêu nhằm đánh giá kết quả làm mỏng thì đầu vat đùi trước ngoài trong phẫu thuât tao hình. Nghiên cứu thực hiện trên 24 bệnh nhân với tổn khuyết được tao hình che phủ bằng vat đùi trước ngoài (ĐTN) làm mỏng thì đầu tại khoa Phẫu thuật tạo hình- Bệnh viện Xanh Pôn và khoa Phấu thuât tao hình - Bểnh viển Bạch Mai từ 01/2017 đến 08/2021. Trong đó, 23/28 vat $(82.14 \%)$ làm mỏng sơ cấp lấy bỏ lớp cân mõ sâu sử dụng kéo Mayo và 5/28 vạt (17.86\%) làm mỏng vi phẫu tích dưới kính hiển vi phấu thuật lấy bỏ thêm một phân lớp mõ̃ nông. Đảo cân mỡ quanh mạch xuyên kích thước nhỏ nhất $1.5 \times 1.5 \mathrm{~cm}$. Kết quả vạt sống hoàn toàn $26 / 28$ vạt $(92.86 \%)$, vạt thiểu dưỡng hoại tử một phần $2 / 28$ vạt (7.14\%), diện tích trung bình vat làm mỏng là $139.11 \pm 67.95 \mathrm{~cm}^{2}$, vat lớn nhất được làm mỏng có kích thước $322 \mathrm{~cm}^{2}$, độ dày trung bình vạt sau làm mỏng $0.49 \pm 0.12 \mathrm{~cm}$, vạt mỏng nhất thu được dày $0.3 \mathrm{~cm}$. Kết quả gần vạt che phủ tốt, liền thương tốt, kết quả xa bênh nhân hài lòng về mắt thẩm mỹ và chức năng. Như vậy vạt ĐTN làm mỏng thì đâu có thể được sữ dụng linh họat, an toàn, hiệu quả trong tạo hình che phủ tổn khuyết ở nhiều vùng trên cơ thể đặc biệt những vùng cần độ mỏng để đảm bảo chức năng và tính thẩm mỹ.

Tư khóa: Vạt đùi trước ngoài, làm mỏng sơ cấp, làm mỏng vi phẫu tích, vạt mạch xuyên.

\section{SUMMARY}

\section{ASSESSEMENT OF THE RESULT OF PRIMARY AND MICRODISECTION THINNING ANTEROLATERAL THIGH FLAP IN PLASTIC SURGERY}

Objective of this paper aims to evaluate the result of thinning the anterolateral thigh flap in plastic

*Trường Đại hoc Y Hà Nội

Chịu trách nhiệm chính: Nguyễn Ngọc Tuấn

Email: z29ftth@gmail.com

Ngày nhận bài: 2/8/2021

Ngày phản biên khoa hoc: 27/8/2021

Ngày duyệt bài: 20/9/2021
Trần Thiết Sơn*, Nguyễn Ngọc Tuấn*, Phạm Thị Việt Dung*, Tạ Thị Hồng Thuý* surgery. The study was carried out on 24 patients who underwent ALT flap thinning at the Department of Plastic surgery of Saint Paul Hospital and Bach Mai Hospital between January 2017 to August 2021. Primary thinning was performed on 23 out of 28 flaps $(82.14 \%)$ to remove the deep adipose tissue with Mayo scissors and microdissected thinning by microscopy was performed on the remaining 5 flaps $(17.86 \%)$ to remove an extra part of superficial adipose tissue. ALT thinning flap was harvested with $1.5 \times 1.5 \mathrm{~cm}$ of minimal deep fascial spared. Complete flap survival in 26 out of 28 flaps $(92.86 \%)$, partial flap necrosis in the remaining 2 flaps $(7.14 \%)$; average flap thinning area was $139.11 \pm 67.95 \mathrm{~cm}^{2}$, the largest flap was $322 \mathrm{~cm}^{2}$, the average flap thickness after thinning was $0.49 \pm 0.12 \mathrm{~cm}$, the thinnest flap obtained was $0.3 \mathrm{~cm}$. The short term result showed flaps with good coverage and good healing. Moreover, patients were satisfied with aesthetic and functional results in long-term follow-ups. In conclusion, the primary or microdissection ALT flap can be used multipurposely, safely, and effectively in plastic surgery to cover defects in various areas that need thinned flaps to improve functional and aesthetic results.

Keyword: Anterolateral flap, primary thinning, microdissection thinning, perforator flap.

\section{I. ĐăT VẤN ĐỀ}

Năm 1984, lần đầu tiên Song Y.G và cộng sự thông báo nghiên cứu về giải phẫu của vạt đừi trước ngoài (Anterolateral thigh Flap- ALT Flap) như là môt vat da cân có thể dùng với kỹ thuật vi phẫu. Kể từ đó đến nay, với những ưu điểm nổi bật của vạt này như: cuống mạch dài, tương đối hằng định về giải phẫu, đường kính lớn, vị trí cho vạt thuận lợi, vạt có thể lấy được kích thước lớn, vạt có thần kinh cảm giác, nơi cho vạt ít ảnh hưởng đến chức năng và thẩm mỹ $\tilde{y}^{1,2}$, nên vạt ĐTN đã trở thành 1 vạt da được sử dụng phổ biến nhất bởi tất cả các nhà tạo hình với nhiều mục đích khác nhau, nhiều vị trí khác nhau trên 
cơ thể. Tuy nhiên, điểm hạn chế của vat ĐTN là vạt có lớp mõ quá dày ${ }^{3}$, đặc biệt trền những bệnh nhân thừa cân, béo phì hoặc trên phụ nữ. Khi vạt quá dày để làm mỏng vạt có thể thực hiện sau phẫu thuật tạo hình bằng cắt mõ̃ thừa, hút mõ̃ hoặc làm mỏng trong thì phẫu thuật đầu tiên. Từ những năm 1990 đã đề cập tới khái niệm làm mỏng vạt $s$ cốp (primary thinning) và tiếp đến năm 2002, Kimura lần đầu tiên đề xuất kỹ thuật vi phẫu tích (microdissection) với mục đích làm mỏng đến mức tối đa các vạt da cần mạch xuyên, đây được coi là bước ngoặt trong phẫu thuật tạo hình ${ }^{4}$. Kỹ thuật làm mỏng vạt thì đầu tại Việt Nam hiện chưa được sử dụng rộng rãi do lo ngại rằng vạt làm mỏng gây ảnh hưởng bất lợi tới cấp máu cho vạt, cùng với đó là có nhiều quan điểm cho rằng làm mỏng vat ĐTN thì đầu không an toàn. Do đó, mục đích của báo cáo này nhằm: Đánh giá kết quả làm mỏng vạt ĐTN trong phẫu thuật và khẳng định tính an toàn của kỹ thuật làm mỏng vạt trong phẫu thuậ tạo hình.

\section{II. ĐỐI TƯỢNG VÀ PHƯƠNG PHÁP NGHIÊN CỨU}

2.1. Đối tượng nghiên cứu. Nghiên cứu trên 24 bệnh nhẩn với các khuyết tổn phần mềm có chỉ định sử dụng vạt đùi trước ngoài tạo hình che phủ, với tổng số 28 vạt mạch xuyên được làm mỏng thì đầu từ $1 / 2017$ đến $8 / 2021$. Nghiển cứu được thực hiên tai khoa Phẫu thuât tao hình - Bệnh viện Xanh Pồn và Khoa Phẫu thuật tạo hình thẩm mỹ - Bệnh viện Bạch Mai.

\subsection{Phương pháp nghiên cứu}

2.2.1. Thiết kế nghiên cứu: Nghiên cứu mô tả, cắt ngang.

\subsubsection{Quy trình phẫu thuật \\ Chuẩn bi trước mổ:}

- Khám toàn trạng bệnh nhân, đo cân nặng, chiều cao, tính BMI, đo chiều dài đùi, vòng đùi. Đánh giá tổn thương cần tạo hình, vị trí, diện tích, xác định mục tiêu tạo hình. Chụp phim MSCT, siêu âm dopller xác định nhánh xuống động mạch mũ đùi ngoài, nhánh xuyên. Thiết kế trước đường mổ dư kiến và kích thước thước vạt.

Các bước phẩu thuật: Dưới vô cảm toàn thân, tiến hành phẫu thuật song song 2 kíp:

Kíp 1: Chuẩn bị nền nhận bao gồm cắt lọc, làm sạch tổn thương, kích thước khuyết tổn sau cắt lọc. Lựa chọn và bộc lộ mạch nhận gồm động mạch và 1 hoăc 2 tĩnh mạch.

Kíp 2: Phẫu tích vạt và làm mỏng vạt

Phẫu tích vạt ĐTN: Đường rạch da phía trước đường trục trên tới tận cân sâu cho phép bộc lộ bờ trước của vạt. Xác định được đường đi của nhánh xuống từ động mạch mũ đùi ngoài, phẫu tích mạch xuyên. Đo chiều dày vạt, thiết kế vạt dựa theo kích thước tổn thương.

Làm mỏng vạt: Làm mỏng vạt sơ cấp: Nhận định các đặc điểm mạch xuyên đi vào vạt, hướng mạch xuyên, xác định kích thước đảo cân để lại. Quan sát rõ hình ảnh lớp cân mõ̃ và lớp cân sầu để xác định ranh giới an toàn. Lớp mõ sâu cùng cân sâu được loại bỏ tới lớp cân nông bằng kéo

Mayo. Vừa loại bỏ mõ thừa vừa theo dõi màu sắc máu chảy ra từ vạt. Một đảo cân kích thước tối thiểu khoảng $1.5 \mathrm{~cm}$ cùng mõ quanh mạch xuyên được để lại. Đo lại chiêu dày của vạt sau khi làm mỏng sơ cấp.

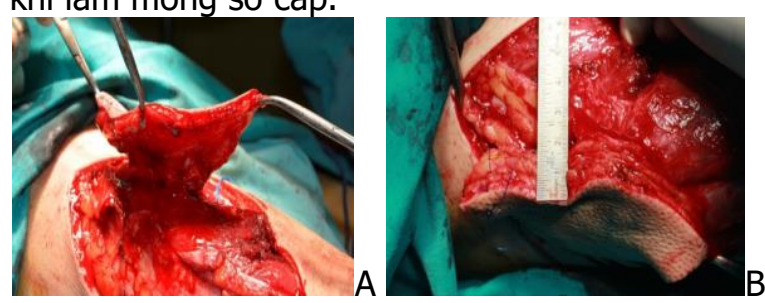

Hình 1. (A)-Vạt đùi trước ngoài sau khi được bóc tách dưới cân, nâng vạt lên. (B)-Hình ảnh nâng vạt lên sau khi đã làm mỏng sơ câp.

Làm mỏng vạt vi phẫu tích: theo kỹ thuật của Trần Thiết Sơon ${ }^{5}$ quan sát hướng vào da của mạch xuyên để quyết định có thực hiện kỹ thuật hay không. Dưới kính hiển vi, ngoài loại bỏ hoàn toàn lớp cân mõ sâu còn loại bỏ một phần lớp mõ nông, hướng phẫu tích theo trục dọc của vạt để bảo tôn tối đa các mach máu nhỏ. Sau khi làm mỏng đến vòng tròn bán kính tối thiểu $2 \mathrm{~cm}$ xung quanh mạch xuyên thì dừng lại. Đo chiều dày vat sau khi đã làm mỏng vi phấu tích.
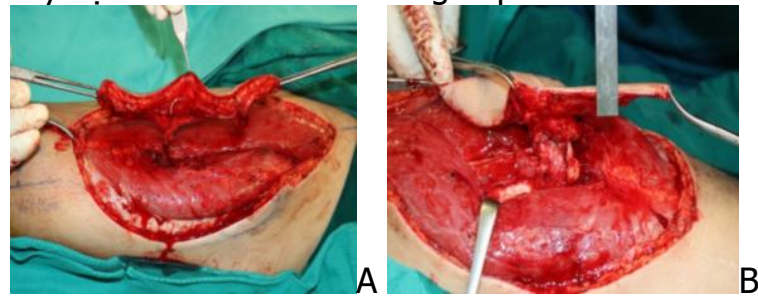

Hình 2. Làm mỏng vi phẫu tích: (A)-Chiều dày vạt trước làm mỏng (B)- Vạt sau khi làm mỏng vi phẫu tích

Tạo hình tổn khuyết: Chuyển vạt tới nơi nhận tạo hình che phủ tổn khuyết, phục hồi lại tuần hoàn vat bằng kỹ thuật vi phẫu. Đóng nơi cho vạt trực tiếp hoặc sử dụng vạt tại chỗ, ghép da mỏng.

\section{Đánh giá kết quả tạo hình}

- Kết quả gần: sự sống của vạt, mức độ che phủ và liền sẹo nơi tạo hình, biến chứng.

- Kết quả xa sau 3-6 tháng: Tốt: Vạt sống toàn bộ, đảm bảo tạo hình che phủ và chức năng nơi 
nhận vạt bình thương. Khá: Vạt đảm bảo vai trò tạo hình che phủ, có thể cần sửa chữa bổ sung. Kém: Vạt quá dày, không đảm bảo vai trò tạo hình, cần phẫu thuật làm mỏng thì hai.

\section{KẾT QUẢ NGHIÊN CứU}

Nghiên cứu tiến hành trên 24 bệnh nhân với tổng số 28 vạt ĐTN được làm mỏng ngay trong phẩu thuật thì đầu. Trong số 24 bệnh nhân làm mỏng thì một có $18 / 24$ bệnh nhân nam (75\%), có $6 / 24$ bệnh nhân nữ (25\%). Tuổi trung bình
$31.91 \pm 13.96$, trung bình BMI là 21.41 2.81 $\mathrm{kg} / \mathrm{m}^{2}$. Vị trí tổn thương phân bố theo vùng cổ bàn chân $18 / 24(75 \%)$, cổ bàn tay $4 / 24$ $(16.67 \%)$, mặt cổ có 2/24 (8.33\%). Nhóm nguyên nhân tổn thương phần lớn do chấn thương tai nạn giao thông với 12/24 bệnh nhân (chiếm 50\%). Tổng số 24 bệnh nhân sử dụng 28 vạt da mõ được làm mỏng bao gồm 20 bệnh nhân sử dụng 1 vat da mỡ và 4 bênh nhân sử dụng dạng vạt chùm với 2 vạt da mõ̃.

Bảng 1. Đặc điểm vạt ĐTN được làm mỏng $(n=28)$

\begin{tabular}{|c|c|c|c|c|c|c|}
\hline $\begin{array}{l}\text { Kỹ thuâat } \\
\text { làm mỏng }\end{array}$ & $\begin{array}{c}\text { Số } \\
\text { lượng } \\
\text { (n) }\end{array}$ & $\begin{array}{c}\text { Diện } \\
\text { tích vạt } \\
\left(\mathbf{c m}^{2}\right)\end{array}$ & $\begin{array}{l}\text { Chiêuu dày } \\
\text { vạt trước } \\
\text { làm mỏng } \\
\text { (cm) }\end{array}$ & $\begin{array}{l}\text { Chiêu dày } \\
\text { sau làm } \\
\text { mỏng }(\mathrm{cm})\end{array}$ & $\begin{array}{l}\text { Phân trăm } \\
\text { độ dày } \\
\text { cồn lại } \\
(\%)\end{array}$ & $\begin{array}{l}\text { Kích thước } \\
\text { đảo cân để } \\
\text { lại nhỏ nhất } \\
(\mathrm{cm})\end{array}$ \\
\hline Sơ cấp & 23 & $35-322$ & $1.0-3.5$ & $0.4-0.8$ & $24-50$ & $1.5 \times 1.5$ \\
\hline Vi phấu tích & 5 & $65-252$ & $1.0-2.0$ & $0.3-0.5$ & $15-33$ & $2 \times 2$ \\
\hline Tống số & 28 & & & & & \\
\hline
\end{tabular}

Với tổng cộng 30 mạch xuyên được sử dụng trong tất cả các trường hợp. Trong đó có $26 / 28$ vat (92.86\%) có một mạch xuyên duy nhất và $02 / 28$ vạt (7.14\%) có 2 mạch xuyên, không có vạt nào sử dụng 3 mạch xuyên. Vị trí mạch xuyên đi vào vạt phân lớn là ở trung tâm vạt (53.33\%), đi vào $1 / 3$ trên vạt và $1 / 3$ dưới vạt với tỷ lệ bằng nhau (23.34\%).
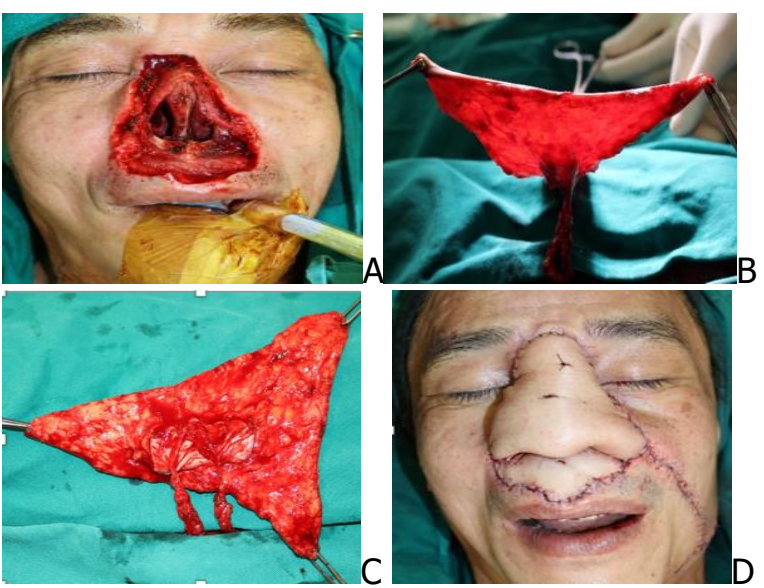

Hình 3. Bênh nhân ung thư tế bào vảy mưi- môi trên. (A)-Khuyết mũi toàn bộ sau khi cắt u.

(B),(C)-Vạt DTN tạo hình mũi được làm mỏng sơ cấp. (D)-Kêt quả sau mổ.

Trong 28 vạt ĐTN làm mỏng thì đầu của chúng tôi, kết quả gần có 02 bệnh nhân biến chứng hoại tử một phần xa nhất của vạt (7.14\%), 02 bệnh nhân bị tụ máu dưới vạt (7.14\%). Theo dõi xa cho kết quả 21/23 vat $(91.3 \%)$ làm mỏng sơ cấp cho kết quả tốt đển khá, $2 / 23$ vạt $(8.7 \%)$ kết quả kém, cần làm mỏng thì hai. $5 / 5$ vạt làm mỏng vi phấu tích cho kết quả tốt.

\section{BÀN LUÂ̂N}

Nhằm mục đích tạo hình che phủ tổn khuyết da vùng mặt cổ, cổ bàn tay, cổ bàn chân, việc lựa chọn được các vạt có độ mỏng thích hợp là một vấn đề khó khẳn đối với các phẫu thuật viển. Độ dày lớp mõ dưới da, giới tính, tuổi, BMI là những yếu tố ảnh hưởng nhiều tới chiều dày của vạt ĐTN. Hiện này, có 2 phương pháp làm mỏng vat chính được áp dung, đơn giản nhất là làm mỏng vạt thì hai sau lần mổ đầu tối thiểu là 3 tuần. Cách thứ hai là làm mỏng vạt ngay trong mổ (sơ cấp hoặc làm mỏng vi phấu tích), được tiến hành ngay sau khi phẩu tích nâng vạt lên. Chúng tôi chỉ nghiên cứu sử dụng kỹ thuật làm mỏng thì đâuu đầu.

Về nguyên nhân và đặc điểm thương tổn chúng tôi nhận thấy khá đa dạng, phong phú với nhiều hình thái khác nhau, với thương tổn chủ yếu là khuyết da rộng che phủ vùng mặt cổ, khuỷu tay, cổ bàn chân. Diện tích khuyết tổn da rất thay đổi, kích thước thương tổn lớn nhất lên tới $23 \times 14 \mathrm{~cm}$ và nhỏ nhất là $7 \times 5 \mathrm{~cm}$.

Trong nghiên cứu của chúng tôi, vạt được làm mỏng sơ cấp, làm mỏng sau khi phẫu tích vạt dưới mặt phẳng cân sâu. Cách làm mỏng này có rất nhiều ưu điểm: dễ dàng phẫu tích vạt, nâng vạt lên, xác định chính xác được vị trí mạch xuyên, hướng mach xuyên đi vào vạt. Làm mỏng vạt sơ cấp có thể tiến hành trên toàn bộ bề mặt vạt hoặc chỉ một phần tùy thuộc vào mục đích tạo hình che phủ đơn thuần hay kèm thêm độn. Nó cũng là phương pháp chuẩn bị vạt tốt để tiến hành làm mỏng vi phẫu tích khi cần. Hệ thống mạch máu trong da từ mạch xuyên vào đùi đã 
được nhiều tác giả nghiên cứu, Kimura ${ }^{6}$ phân chúng thành 3 type, và với dạng mạch xuyên type 2 việc tiến hành làm mỏng vạt sơ cấp và bảo tồn khối mõ $2 \mathrm{~cm}$ quanh mạch xuyên là an toàn. Tổng 23 vạt làm mỏng sơ cấp có diện tích vạt trung bình là $136.09 \pm 69.16 \mathrm{~cm}^{2}$, kích thước đảo cân để lại bé nhất là $1.5 \times 1.5 \mathrm{~cm}$, độ dày trung bình vạt trước làm mỏng là $1.88 \pm 0.72 \mathrm{~cm}$, độ dày vạt sau làm mỏng trung bình là $0.5 \pm 0.11 \mathrm{~cm}$, phần trăm độ dày vạt còn lại là $29.52 \pm 9.67 \%$. Trong đó vạt mỏng nhất là $0.4 \mathrm{~cm}$, vạt dày nhất là $0.8 \mathrm{~cm}$. Có 2 ca hoại tử vạt một phần ở phần xa nhất của vạt chiếm tỷ lệ $7.14 \%$. Khi so sánh kết quả với nghiên cứu của Safa E. Sharabi ${ }^{7}$ về tương quan diện tích làm mỏng vạt với tỷ lệ biến chứng, nhóm bệnh nhân vạt diện tích nhỏ hơn $150 \mathrm{~cm} 2(\mathrm{n}=61$, diện tích vạt $123.19 \mathrm{~cm} 2$ tỷ lệ biến chứng mạch máu $6.56 \%)$ nhóm bênh nhân lớn hơn $150 \mathrm{~cm} 2$ ( $n=27$, diện tích vạt $180.73 \mathrm{~cm} 2$, tỷ lệ biến chứng $25.93 \%$ ). Điều này cho thấy rõ ràng khi làm mỏng vạt $A L T$ kích thước càng lớn và khi lớn hơn $150 \mathrm{~cm} 2$ thì tỉ lệ biến chứng vạt tăng rõ rệt. Kích thước an toàn của vat làm mỏng đã được báo cáo có thể lên tới $17-18 \mathrm{~cm}$ trong các nghiên cứu lâm sàng khác nhau². So với các tác giả trên, chúng tôi có tỷ lệ thành công rất cao, thậm chí ở cả những vạt kích thước lớn. Trong 23 vạt của chúng tôi, vạt nhỏ nhất kích thước $35 \mathrm{~cm}^{2}$, vạt lớn nhất lên tới $322 \mathrm{~cm}^{2}$ mà không có hoại tử vạt. Đối với những vạt kích thước lớn $\left(>240 \mathrm{~cm}^{2}\right)$ theo Viviano ${ }^{8}$, tác giả khuyến cáo chỉ nên làm mỏng vạt phía ngoại vi, để lại đảo cân mõ kích thước lển tới $6-8 \mathrm{~cm}$, sẽ an toàn cho vạt. Với chiều dày trung bình sau làm mỏng là $0.5 \mathrm{~cm}$, làm mỏng vạt ĐTN sơ cấp thường được chỉ định cho tạo hình che phủ khuyết phần mềm đợn giản, dạng phẳng, vùng gót chân, mă̆t sau cẳng chân, cẳng tay khủy tay, vạt không cẩn phải quá mỏng như tạo hình vùng cổ bàn ngón tay, cổ chân, mu bàn chân. Bên cạnh đó, chiều dày sau làm mỏng sơ cấp vạt ĐTN phụ thuộc vào chiêu dày vạt ban đầu, BMI bệnh nhân, do đó độ mỏng vạt tối đa đã hằng định trước khi tiến hành làm mỏng trên từng bệnh nhân cụ thể và bằng chính chiêu dày lớp da và lớp mõ nông, không thể làm mỏng hơn nếu chỉ sử dụng kỹ thuật làm mỏng sơ cấp đơn thuần.

Năm vạt làm mỏng vi phẫu tích chỉ định cho các trường hợp khuyết sau cắt bỏ sẹo cổ mặt, sẹo co khủy tay, khuyết toàn bộ da bàn tay, khuyết da mu chân và khuyết phần mềm ngón cái bàn tay. Trong nghiên cứu của chúng tôi, vấn đề làm mỏng toàn bộ vạt bằng kỹ thuật vi phẫu tích được thực hiện khá thành công, vạt được làm mỏng tối đa còn $0.3 \mathrm{~cm}$ chiều dày. Sau khi làm mỏng sơ cấp mà chưa đạt được độ dày vạt theo yêu cầu, vạt sẽ tiếp tục được làm mỏng dưới kính hiển vi (microdissection thinning)phương pháp làm mỏng này có thể quan sát rõ ràng được đường đi mạch xuyên, các nhánh của nó để tránh làm tổn thương khi loại bỏ các thùy mơ. Tiến hành làm mỏng vạt theo trục dọc dưới kính vi, dựa trên hướng cấp máu ưu tiên và hướng của các kết nối tuần hoàn giữa các perforasome với nhau, dựa trên dòng chảy áp lực lớn của vạt như Song và cộng sự mô tả, sự mở kênh tuần hoàn phụ trong vùng huyết động và vùng tiềm tàng, sự tồn tại phong phú của mạng mạch dưới da ${ }^{5}$. Việc bảo tồn được hệ thống mạch máu trong da cùng với việc loại bỏ lớp mõ̃ thừa giúp chúng tôi kiểm soát chủ động chiều dày vạt da, không còn bị phụ thuộc bởi chiều dày vạt da trước làm mỏng.

Trong 28 vạt ĐTN làm mỏng của chúng tôi, 02 bệnh nhân có biến chứng hoại tử một phần xa nhất của vạt, được khắc phục bằng cách cắt lọc phần tổ chức hoại tử sau 10 ngày và đóng trực tiếp vết mổ. Hai bệnh nhân bị tụ máu dưới vạt là 2 bệnh nhân được làm mỏng vi phẫu tích, phát hiện và xử trí ngay trong 24 giờ đầu bằng cách mổ cấp cứu, lấy máu tụ, sau mổ vạt sống hoàn toàn, liên thương tốt. Đây cũng là biến chứng sớm đáng lo ngại nhất của kỹ thuật làm mỏng vi phẫu tích, khi không cầm máu kĩ bề mặt vạt sau khi làm mỏng, dẫn tới tăng nguy cơ chảy máu dưới vạt sau mổ. Do đó đối với những bệnh nhân được làm mỏng vi phẫu tích, theo dõi sau mổ thường xuyên để phát hiện sớm biến chứng chảy máu, tụ máu dưới vạt để giải quyết kịp thời, cứu sống vạt.

\section{KẾT LUẬN}

Vạt ĐTN làm mỏng được sử dụng rất linh hoạt, thích hợp cho những tổn khuyết đặc biệt vùng mặt cổ, bàn tay... Làm mỏng vạt đùi trước ngoài là kỹ thuật an toàn, giải quyết được nhược điểm lớn nhất của vạt ĐTN là vạt quá dày. Làm mỏng vạt đúng kỹ thuật không làm tăng nguy cơ hoai tử vạt và mang lại hiệu quả tốt. Tuy nhiên cần tới sự hiểu biết giải phẫu và phẫu thuật viên phải rất cỏ kinh nghiệm sử dụng vạt ĐTNं cũng như kinh nghiệm phẫu tích.

\section{TÀI LIÊU THAM KHẢO}

1. Song $\mathbf{Y}$, Chen $\mathbf{G}$, Song $\mathbf{Y}$. The free thigh flap: a new free flap concept based on the septocutaneous artery. Br J Plast Surg. 1984;37(2):149-159.

2. Shieh SJ, Chiu HY, Yu JC, Pan SC, Tsai ST, 
Shen CL. Free anterolateral thigh flap for reconstruction of head and neck defects following cancer ablation. Plast Reconstr Surg. 2000;105(7):2349-2357; discussion 2358-2360.

3. Cigna $E$, Minni $A$, Barbaro $M$, et al. An experience on primary thinning and secondary debulking of anterolateral thigh flap in head and neck reconstruction. :7.

4. Kimura N. A microdissected thin tensor fasciae latae perforator flap. Plast Reconstr Surg. 2002;109(1):69-77; discussion 78-80.

5. Trân Thiết Sơn. Ứng dụng kỹ thuất vi phẫu tích trong phẫu thuật tạo hình. Tạp chí y học. J Med Res. Published online December 2011:1-6.
6. Kimura $\mathbf{N}$, Satoh $K$, Hasumi $T$, Ostuka $T$. Clinical application of the free thin anterolateral thigh flap in 31 consecutive patients. Plast Reconstr Surg. 2001;108(5):1197-1208; discussion 1209-1210.

7. Sharabi SE, Hatef DA, Koshy JC, Jain A, Cole PD, Hollier LH. Is Primary Thinning of the Anterolateral Thigh Flap Recommended?: Ann Plast Surg. 2010;65(6):555-559.

8. Viviano SL, Liu FC, Therattil PJ, Lee ES, Keith JD. Peripheral Pruning: A Safe Approach to Thinning Extra-Large Anterolateral Thigh Flaps. Ann Plast Surg. Published online March 2018:1.

\section{ĐỊNH LƯỢNG CẦN SA TỔNG HỢP 5-FLUORO-MDMB-PICA Có TRONG MẪU MA TÚY BẰNG PHƯƠNG PHÁP SẮC KÝ KHÍ GHÉP ĐÂUU DÒ KHỐI PHỔ}

\section{TÓM TẮT}

Mục tiêu: Xây dựng quy trình định lượng chấtcần sa tổng hợp 5-FLUORO-MDMB-PICA có trong mấu ma túy thu thập được bằng phương pháp sắc ký khí ghép đâuu dò khối phố (GC-MS). Đối tượng và phương pháp: Mẫu cần sa tổng hợp chứa trong các dạng cỏ Mỹ được thu thập trong các vụ án tại Việt Nam từ năm 2018 đến 2020, được xử lý và dùng làm mẫu thử để thẩm đinh quy trình định lượng 5-FLUORO-MDMBPICA bằng phương pháp GC-MŚ theo hướng dẫn của ICH. Kết quả: Quy trình phân tích,đinh lương 5FLUORO-MDMB-PICA, đã xác định được điều kiện sắc ký khí GC-MS thích hợp để pic 5-FLUORO-MDMB-PICA tách hoàn toàn với các pic khác. Quy trình định lượng đã được thẩm định về độ lặp lại và độ đúng phừ hợp để định lượng 5-FLUORO-MDMB-PICA trong mẫu cỏ Mỹ với giới hạn phát hiện là $0,06 \mu \mathrm{g} / \mathrm{mL}$. Hàm lượng trung bình của 5-FLUORO-MDMB-PICAtrong cỏ Mỹ được xác định nằm trong khoảng $2,2 \mathrm{mg}$ tính trên $100 \mathrm{mg}$ cỏ Mỹ (2,2\%). Kết luận: Lần đầu tiên tại Việt Namquy trình định lượng5-FLÜORO-MDMB-PICA trong mấu cỏ Mỹđã được xây dựng và thẩm định.Quy trình đơn giản, nhanh, ít tốn kém, kết quả có độ lặp lại cao và độ đúng đáng tin cậy. Quy trình đạt tất cả các yêu cầu thẩm định theo hướng dẫn của İCH. Với các ưu điểm trên, quy trình này cóthể định tính, định lượng nhanh, chính xác và đượcápdụngrộngrãitrongđiều kiện các phòng thí nghiệm giám định ma túy ở Việt Nam, góp phân định hướng xây dựng quy trình giám định các chất ma túy cần sa tông hợp mớicho các cơ quan chức năng, xây dựng tiêu chuẩn quốc gia về An Ninh trong đấu tranh phòng chống tội phạm về ma túy.

*Đại học Y Dước TP. Hồ Chí Minh

**Phân viên Khoa hoc hinh sư tai TPHCM

Liên lạc để tài: Nguyễn Hùng Cường

Email: hungcuongkndc@gmail.com

Ngày nhận bài: 7/8/2021

Ngày ohanr biên khoa học: 28/8/2021

Ngày duyệt bài: 20/9/2021
Nguyễn Hùng Cường*, Nguyễn Đăng Tiến**

Tư khóa: Cần sa tổng hợp, 5-FLUORO-MDMBPICA, GC-MS.

\section{SUMMARY}

DETERMINATION OF SYNTHETIC CANNABINOID 5-FLUORO-MDMB-PICA IN NARCOTIC DRUGS BY GAS

CHROMATOGRAPHY MASS SPECTROMETRY

Objectives:A gas chromatography mass spectrometry (GC-MS) method was developed and validated for 5-FLUORO-MDMB-PICA innarcotic drugs. Subjects and methods: Synthetic cannabis samples contained in American grass collected in criminal cases in Vietnam from 2018 to 2020, were processed and used as test samples to validate the 5-FLUOROMDMB-PICA GC-MS analyticalmethod according to ICH guidelines. Results: The 5-FLUORO-MDMB-PICA analytical, method was successfully developed withappropriate chromatographic conditions. The procedure was validatedwith suitablerepeatability and accuracywith a detection limit of $0,06 \mu \mathrm{g} / \mathrm{mL}$. The average content of 5-FLUORO-MDMB-PICA in American grass was determined to be in the range of $2.2 \mathrm{mg}$ per $100 \mathrm{mg}$ of American grass(2,2\%). Conclusions: For the first time in Vietnam, theanalytical method to determine 5-FLUORO-MDMBPICA in American grass samples has been developed and validated. The process is simple, fast, inexpensive, and the results are highly reproduciblewith reliable, accuracy. The methodsatisfies all requirements according to $\mathrm{ICH}$ guidelines. Conclusively, this processcouldhelp to identify and quantify quickly and accuratelythe 5FLUORO-MDMB-PICA incriminalevidences, andcan be widely applied in drug testing laboratories in Vietnam. This work, contributes to themethod development of assessing new synthetic cannabinoids, and develop national security standards in the fight against drugrelated crimes.

Key words: Synthetic cannabinoids, 5-FLUOROMDMB-PICA, GC-MS. 